\title{
Princípios da administração fayolista na administração escolar paraense na década de 1920: os relatórios de Aurelia de Seixas Franco
}

\section{Principles of fayolist administration in paraense school administration in the 1920s: the reports of Aurelia de Seixas Franco Principios de la administración fayolista en la administración escolar paraensa en los años 1920: los informes de Aurelia de Seixas Franco}

\author{
MONIKA RESCHKE \\ Orcid Id: http://orcid.org/0000-0002-4756-9179 \\ Universidade Federal do Pará \\ ALBERTO DAMASCENO \\ Orcid Id: http://orcid.org/0000-0003-1620-6735 \\ Universidade Federal do Pará
}

\begin{abstract}
Resumo: $\mathrm{O}$ artigo tem como objetivo identificar os princípios da administração do Grupo Escolar Benjamin Constant de 1922 a 1927, a partir dos relatórios da diretora Aurélia de Seixas Franco. Para tanto, realizamos uma pesquisa bibliográfica e documental, a qual nos possibilitou inferir que as práticas administrativas da diretora se aproximavam dos princípios do Fayolismo, em um momento no qual o estado do Pará passava por uma crise financeira que afetava o funcionamento da rede escolar como um todo, prejudicando a consolidação do ideário republicano na instrução pública.
\end{abstract}

Palavras-chave: Grupo Escolar Benjamin Constant. Primeira República. Administração Escolar. Fayolismo.

\begin{abstract}
The article aims to identify in the reports of the director Aurélia de Seixas Franco the principles of the administration of the Benjamin Constant School Group from 1922 to 1927. For this purpose, we conducted bibliographic and documentary research, which allowed us to infer that the administrative practices of the principal approached the principles of Fayolism, at a time when the state of Para was going through a financial crisis that affected the functioning of the school network as a whole, hampering the consolidation of the republican ideology in public education.
\end{abstract}

Keywords: Benjamin Constant School Group. First Republic. School Administration. Fayolism. 
Resumen: El articulo tiene como objetivo identificar en los informes de la directora Aurélia de Seixas Franco los principios de la administración del Grupo Escolar Benjamin Constant de 1922 a 1927. Para este propósito, realizamos una investigación bibliográfica y documental, que nos permitió inferir que las prácticas administrativas de la directora se acercaban a los principios del Fayolismo, en un momento en que el estado de Pará atravesaba una crisis financiera que afectó el funcionamiento de la red escolar en su conjunto, obstaculizando la consolidación de la ideología republicana en la educación pública.

Palabras clave: Grupo Escolar Benjamin Constant. Primera República. Administración escolar. Fayolismo.

\section{INTRODUÇÃO}

O presente artigo situa-se no campo da História da Educação em interface com a política educacional, mais especificamente propondo uma reflexão sobre a Administração Escolar na Primeira República a partir de documentos da década de 1920 que foram manuscritos por Aurelia de Seixas Franco, então diretora do Grupo Escolar Benjamin Constant. O referido grupo foi criado no mandato do governador Augusto Montenegro, por meio do Decreto n .1067 , de 12 de agosto de 1901, sob a denominação "Segundo Grupo Escolar da Capital”, posteriormente denominado "Grupo Escolar Benjamin Constant". Foi implantado na cidade de Belém, em um prédio arrendado pelo governo para esse fim.

Essas fontes estavam disponíveis no arquivo da escola e são compostas por quatro relatórios administrativos produzidos entre os anos de 1922 e 1927. Apesar das dificuldades encontradas para seu manuseio - em razão de estarem corroídas pelo tempo e por insetos - a experiência foi significativa, pois nos permitiu visualizar uma descrição, mesmo que fragmentária, da estrutura e do funcionamento da escola naqueles anos. Para investigarmos a administração escolar desse período, realizamos uma pesquisa bibliográfica e documental. A primeira foi realizada em livros, artigos e sites; já a segunda, em decretos, regulamentos, jornais, imagens, revistas, relatórios da diretora Aurelia, entre outros documentos. Alguns desses ainda não haviam passado por um tratamento analítico. Em relação aos documentos, buscamos encontrar conexões com a realidade da sociedade da época e sua relação com a instituição escolar,

assim como uma determinada sociedade foi condição para a criação e o desenvolvimento de uma determinada instituição escolar, esta é condição de existência daquela, porque lhe molda suas relações de produção, sem esquecer, porém, que, na produção da escola, a sociedade opera de forma conflituosa, pois suas opostas classes sociais lutam, em opostos campos, em favor de escolas que atendam aos seus próprios interesses (NOSELLA; BUFFA, 2009, p. 80). 
Assim, foi possível compreender que, com a implantação do regime republicano, muitas mudanças foram observadas no Brasil em busca de consolidar uma nova sociedade. Essa conjuntura afetou a instrução pública, que passou por transformações. Dentre elas, está o surgimento de um novo modelo de escola primária materializado pelos grupos escolares, que passaram a exigir uma nova organização, com graduação seriada, unificação de métodos de ensino e controle mais rigoroso do Estado.

Com a crescente industrialização e urbanização desse período, a escola primária era tida como imprescindível ao projeto de modernização da República, uma vez que crescia a

necessidade de pessoas alfabetizadas, porque as técnicas elementares e necessárias de leitura, escrita e cálculo tornavam-se fatores importantes e necessários para a adaptação ao desempenho de determinadas atividades fundamentais na modernidade. Daí a intensificação de campanhas difundido o ensino (CARVALHO, 2004, p. 33).

Desse modo, uma nova escola foi sendo construída, na qual a administração caberia a um Diretor, que organizaria, coordenaria e fiscalizaria o ensino ali desenvolvido, de acordo com o que propagava o ideário republicano. Nesse momento, surge

[...] um novo profissional do ensino primário, que era representante da escola perante o governo, com o qual geralmente tinha ligação política. Desempenhando funções administrativas e pedagógicas, o diretor era autoridade máxima no grupo escolar. Ele também era o representante da sua escola nas suas relações externas e gozava de prestígio no seu entorno social - ao lado de autoridades políticas, jurídicas e religiosas (TEIVE; DALLABRIDA, 2011, p. 64).

É desse profissional e de sua prática administrativa escolar que iremos tratar nesta pesquisa. Contudo, faz-se necessário esclarecer que optamos por utilizar o termo "administração" em vez de "gestão", pois era a nomenclatura utilizada na época estudada. Além do mais, consideramos que "não se trata de simples mudança terminológica e sim de uma fundamental alteração de atitude e orientação conceitual" (LÜCK, 2000, p. 15), uma vez que a administração, de acordo com Lück (2000), apresenta aspectos sistemáticos, constantes e imutáveis. Já a concepção de Gestão é dinâmica e sofre constantes mutações, pelo fato de não se restringir à "mera aplicação dos métodos, técnicas e princípios da administração empresarial, devido à sua especificidade e aos fins a serem alcançados" (DOURADO, 2007, p. 924). 


\section{A EDUCAÇÃO PÚBLICA NO PARÁ NAS PRIMEIRAS DÉCADAS DO SÉCULO XX}

Com a proclamação da República, a implantação de uma nova escola tornou-se imprescindível e, segundo Souza (1998, p. 27), "um amplo projeto civilizador [...] foi gestado nessa época e nele a educação popular foi ressaltada como uma necessidade política e social". Essa nova perspectiva de organização das instituições escolares foi marcada pela criação dos grupos escolares.

No estado do Pará, o primeiro Grupo foi criado pelo Decreto n ${ }^{\circ} 722$, de 10 de julho de 1899, no interior do Estado, mais especificamente no município de Alenquer, sendo denominado de Grupo Escolar de Alenquer. No ano de 1900, mais cinco grupos foram implantados no interior do Estado, antes da criação do primeiro grupo da capital, que só veio a surgir em 1901, denominado "José Veríssimo". No mesmo ano, foram criados mais três grupos escolares no interior e outros dois na capital, entre os quais o grupo escolar Benjamin Constant, implantado pelo Decreto $n^{\circ} 935$, de 7 de janeiro. Vale ressaltar que esses estabelecimentos foram implantados no estado do Pará durante o governo de Paes de Carvalho, que cumpria seu mandato em condições econômicas bastante satisfatórias, proporcionadas pelos dividendos auferidos pela exportação da borracha. No entanto, na década de 1920, o quadro econômico do estado era bem diferente, pois a exportação do produto sofreu forte declínio graças à concorrência de países asiáticos que derrubou seus preços.

No intervalo de tempo entre os relatórios analisados, Antônio Emiliano de Sousa (entre 1921 e 1925) e Dionísio Bentes (entre 1925 e 1929) governaram o estado sob um quadro de receita estadual bastante precário e problemático, sendo "inferior a quase $50 \%$ das despesas fixadas, o pagamento do funcionalismo público estava atrasado, havia dívidas internas e externas contraídas ao longo dos governos anteriores e o crédito público do governo estava abalado" (COELHO, 2008, p. 10). Essa conjuntura também afetou a instrução pública e, por conseguinte, a gestão de seus estabelecimentos, entre os quais os grupos escolares. Foi nesse cenário que a Diretora Aurelia de Seixas Franco levou a cabo a missão de administrar uma instituição escolar nos moldes dos ideais republicanos, em um estado afundado em uma crise econômica que inviabilizava novos investimentos na manutenção da infraestrutura, na compra de materiais pedagógicos e também no pagamento do funcionalismo público (COELHO, 2008). 


\section{AS BASES TEÓRICAS DA ADMINISTRAÇÃO ESCOLAR NA PRIMEIRA REPÚBLICA}

Segundo Sander (2007, p. 11), a "administração da educação no Brasil nasceu e se desenvolveu no contexto da administração pública e no âmbito da política econômica, científica e cultural do país". A administração escolar se estabeleceu em um contexto pós-Revolução Industrial, que se caracterizou por ser um momento em que havia grande necessidade de organização e controle, de modo que a partir de então "a busca do conhecimento na administração pública e na gestão da educação tem sido e vem sendo uma constante da história das instituições sociais e educacionais em todo o mundo" (SANDER, 2007, p. 12). No Brasil, a busca por conhecimento sobre administração pública e educacional ocorreu com o intuito de encontrar teorias e modelos analíticos, seja no âmbito internacional seja no âmbito nacional; com isso, na busca pela elaboração de teorias e metodologias próprias, a influência externa foi muito marcante, sobretudo em razão da

orientação positivista e funcionalista que dominou o desenvolvimento das ciências sociais na segunda metade do século XIX e na primeira metade do século XX. É nesse contexto histórico que nasceram e se desenvolveram as teorias clássicas e comportamentais de administração, na Europa e nos Estados Unidos (SANDER, 2007, p. 12).

Essas teorias de administração foram difundidas pelo mundo, principalmente após a II Guerra Mundial, momento em que a política desenvolvida era voltada para o comércio e industrialização, as quais apresentavam técnicas de caráter universais, que deveriam ser aplicadas sem levar em consideração os aspectos locais. O Brasil se inseriu justamente nesse processo de aceitação das teorias administrativas produzidas em outros países, com realidades e interesses distintos. Segundo Sander (2007), o pensamento administrativo da educação no Brasil foi organizado em quatro fases oriundas da administração pública: organizacional, comportamental, desenvolvimentista e sociocultural. Nesta pesquisa, o foco é a primeira fase, visto que esta teve um maior destaque e domínio durante o período da Primeira República.

A fase organizacional se instalou em um contexto político e intelectual marcado pela I Guerra Mundial e pela Depressão da década de 1920, que afetou o setor político e educacional, resultando em muitas reformas, entre elas a ocorrida no campo da gestão da educação. Também foi marcada por uma concepção tecnoburocrática, na qual "as considerações políticas, os aspectos humanos e os valores éticos muitas vezes ocupavam lugar secundário” (SANDER, 2007, p. 
28). Assim, a administração da educação passava a relacionar a pedagogia com o pragmatismo, tendo de oferecer respostas técnicas para resolver as dificuldades enfrentadas pelas instituições escolares e pelo próprio sistema de ensino. Era um modelo que podia ser comparado com uma máquina, a qual se preocupava com eficiência, economia e produtividade.

Contudo, esse pensamento enfrentou fortes reações na sociedade brasileira no início do século XX, na medida em que havia no Brasil uma forte tradição do direito administrativo romano, algo que acabou por prejudicar a adoção das soluções pragmáticas, uma vez que essas não conseguiram "apagar as preocupações com a teoria abstrata do enfoque jurídico, que marcou o nascimento e o desenvolvimento de nossas instituições políticas administrativas" (SANDER, 2007, p. 29).

Apesar disso, Sander (2007) aponta que, na fase organizacional, tiveram início todos os trabalhos pioneiros que vieram a influenciar o percurso da administração pública e da gestão da educação no Brasil republicano. O autor ainda enfatiza como tal fase teve por base os princípios da escola clássica da administração, tendo destaque, no período da Primeira República, a administração científica de Taylor (1911) nos Estados Unidos e a administração geral e industrial de Fayol (1916), na França.

Essa influência das teorias da escola clássica, segundo Sander (2007), dificultou para o Brasil um desenvolvimento interdisciplinar mais vinculado à cultura do país, pois os estudos da época se preocupavam muito mais em apresentar aproximações ou distanciamentos da administração pública em relação aos conceitos da administração científica, industrial e burocrática estabelecida pelos expoentes desse período, como Taylor, Fayol e Weber. A adoção do modelo de Taylor, voltado para a produção fabril, produziu na sociedade uma consequente modernização, moldando-a sob "nossos valores, inclusive nossa maneira de conceber a educação e a escola, e dando à nossa sociedade seu feito tecnológico específico" (DOLL JR, 2002, p. 55). Nesse sentido, é possível compreender o diretor escolar como um supervisor de fábrica, com as mesmas atribuições destes, pois como aponta Doll Jr (2002), a industrialização influenciou todos os segmentos da sociedade, inclusive a instituição escolar. Dito isso, é importante evidenciar que foi possível encontrar correspondências significativas entre as ideias de Taylor e Fayol nos relatórios estudados, corroborando aproximações entre a prática de diretora Aurelia e a teoria Taylorista, assim como as ideias de Fayol, partindo das características de seus sistemas, pautados na organização e na divisão de tarefas, com o objetivo de obter o máximo de rendimento e eficiência com o mínimo de tempo e atividade. 
Dessa forma, a partir do surgimento dos grupos escolares, foi construída uma identidade para o gestor e o que ele representava para a sociedade ao desempenhar suas funções como diretor escolar, autoridade respeitada e valorizada pela comunidade com um todo e cujo prestígio se obtinha pelas relações políticas que o cargo oferecia e promovia.

Os estudiosos sobre a administração escolar apontam que os primeiros trabalhos a respeito dessa temática no Brasil só começaram a ser produzidos a partir da década de 1930. Segundo Sander (2007), o que se pode acessar em termos de produção sobre a administração escolar até a Primeira República são "memórias, relatórios e descrições de caráter subjetivo, normativo, assistemático e legalista" (SANDER, 2007, p. 21). Por outro lado, a prática administrativa já existia nas escolas, mesmo que de forma embrionária, de acordo com Rebelatto (2014), em termos de suas características, a organização do ensino na Primeira República foi iniciada "por um caráter normativo e prescritivo" (REBELATTO, 2014, p. 323).

Assim, sem uma teoria própria acerca desse período, o conhecimento em administração escolar que reproduzia o cenário político, econômico e social da época foi construído por meio da relação possível entre educação e sociedade. Assim, concordando com Paro (2012), cabe destacar como a natureza da atividade administrativa pode ser compreendida como um produto da evolução histórica, caracterizada pelas contradições sociais e interesses políticos presentes na sociedade, daí a dificuldade de explorar um período sem uma teoria específica a seu respeito, de modo que só nos foi possível analisar os "critérios para descrição e diagnóstico de situações administrativas" (WAHRLICH, 1974, p. 2). A observação acerca da administração escolar possibilitou "descobrir quais as generalizações, se houver, que dêles podem ser inferidas, a fim de permitir que fenômenos semelhantes possam ser esclarecidos através da aplicação de princípios ou regras" (WAHRLICH, 1974, p. 4).

\section{OS CONTRAPONTOS ENTRE AS TEORIAS E A PRÁTICA}

Buscamos realizar aproximações entre alguns elementos teóricos da fase organizacional sob a ótica de Taylor e Fayol, e a prática da administração escolar realizada no Grupo Benjamin Constant pela diretora Aurelia. O intuito é o de identificar características da prática administrativa no período em análise. Mesmo compreendendo que há características tayloristas na administração dessa época, foi mais patente nos relatórios administrativos de Aurelia Franco a presença de características fayolistas. Por essa razão, partimos para a análise dos documentos tendo por base a teoria clássica de Fayol. 
Em seu livro Administração industrial e geral: previsão, organizaçãa, comando, coordenação controle, antes de definir administração, Henri Fayol apresenta um conjunto de seis operações - técnicas, comerciais, financeira, de segurança, de contabilidade e administrativas - que considera essenciais para a existência de qualquer empresa; dentre essas funções, destaca a administrativa, que é definida da seguinte forma:
Administrar é prever, organizar, comandar, coordenar e controlar.
Prever é perscrutar o futuro e traçar o programa de ação.
Organizar é constituir o duplo organismo, material e social, da empresa.
Comandar é dirigir o pessoal.
Coordenar é ligar, unir e harmonizar todos os atos e todos os reforços.
Controlar é velar para que tudo corra de acordo com as regras estabelecidas e as ordens dadas (FAYOL, 1989, p. 26, grifo do autor).

Além dessa definição, o autor frisa que a função administrativa é diferente da de dirigir, pois esta significa "conduzir a empresa, tendo em vista os fins visados, procurando obter as maiores vantagens possíveis de todos os recursos de que ela dispõe, é assegurar a marcha das seis funções essenciais" (FAYOL, 1989, p. 26). Fayol conclui apresentando a administração como uma das seis operações apresentadas anteriormente, cujo ritmo é "assegurado pela direção. Mas ocupa tão grande lugar nas funções dos altos chefes que, às vezes, pode parecer que elas sejam exclusivamente administrativas" (FAYOL, 1989, p. 26).

Dessa forma, para Fayol (1989), a função administrativa está relacionada com o corpo social da empresa, enquanto as demais estão relacionadas com a matéria-prima e as máquinas. Para o autor, um bom funcionamento desse corpo social exige algumas condições, as quais ele preferiu chamar de princípios, com um total de quatorze. Todavia, destacou que esses não são rígidos nem limitados, mas são os que ele encontrou com mais frequência em sua análise. Para apresentarmos esses princípios, utilizamo-nos de um quadro elaborado por Maximiano (2012).

\section{Quadro 1 - Os princípios de Administração de Fayol}

\begin{tabular}{|c|l|l|}
\hline 1 & Divisão do trabalho & $\begin{array}{l}\text { Designação de tarefas específicas para cada pessoa, resultando na } \\
\text { especialização das funções e separação dos poderes. }\end{array}$ \\
\hline 2 & Autoridade e responsabilidade & $\begin{array}{l}\text { A primeira é o direito de mandar e o poder de fazer-se obedecer. A segunda, } \\
\text { a sanção - recompensa ou penalidade - que acompanha o exercício do } \\
\text { poder. }\end{array}$ \\
\hline 3 & Disciplina & Respeito aos acordos estabelecidos entre a empresa e seus agentes. \\
\hline 4 & Unidade de comando & De forma que cada pessoa tenha apenas um superior. \\
\hline 5 & Unidade de direção & $\begin{array}{l}\text { Um só chefe e um só programa para um conjunto de operações que visam } \\
\text { ao mesmo objetivo. }\end{array}$ \\
\hline
\end{tabular}




\section{Quadro 1 - Os princípios de Administração de Fayol}

\begin{tabular}{|c|l|l|}
\hline 6 & Interesse geral & Subordinação do interesse individual ao interesse geral. \\
\hline 7 & Remuneração do pessoal & De forma equitativa, e com base tanto em fatores internos quanto externos. \\
\hline 8 & Centralização & $\begin{array}{l}\text { Equilibrio entre a concentração de poderes de decisão no chefe, sua } \\
\text { capacidade de enfrentar suas responsabilidades e a iniciativa dos } \\
\text { subordinados. }\end{array}$ \\
\hline 9 & $\begin{array}{l}\text { Cadeia escalar } \\
\text { (linha de comando) }\end{array}$ & $\begin{array}{l}\text { Hierarquia - a série dos chefes do primeiro ao último escalão, dando-se aos } \\
\text { subordinados de chefes diferentes a autonomia para estabelecer relações } \\
\text { diretas (a ponte de Fayol). }\end{array}$ \\
\hline 10 & Ordem & Um lugar para cada pessoa e cada pessoa em seu lugar. \\
\hline 11 & Equidade & $\begin{array}{l}\text { Tratamento das pessoas com benevolência e justiça, não excluindo a } \\
\text { energia e o rigor quando necessários. }\end{array}$ \\
\hline 12 & Estabilidade do pessoal & Manutenção das equipes como forma de promover seu desenvolvimento. \\
\hline 13 & Iniciativa & Faz aumentar o zelo e a atividade dos agentes. \\
\hline 14 & Espírito de equipe & Desenvolvimento e manutenção da harmonia dentro da força de trabalho. \\
\hline
\end{tabular}

Fonte: Maximiano (2012, p. 59).

A partir desses elementos anteriormente mencionados, propusemo-nos a estabelecer relações entre eles e algumas ações administrativas registradas nos relatórios da diretora Aurelia.

Um primeiro princípio se evidenciou ao analisarmos os relatórios nos quais a diretora Aurelia relaciona os nomes dos professores às classes em que atuam.

\section{Corpo docente}

O atual corpo docente deste grupo está assim constituído:

Secção feminina

\section{Escola complementar}

Regente effectiva professora Juventina Damascena Ferreira Sena.

$3^{\text {a }}$ escola elementar

Regente effectiva professora Maria Celestina Baena Camizão, adjunta effectiva Alzira do Espirito Santo Vilhena.

$2^{\mathrm{a}}$ escola elementar

Regente effectiva professora Cantidiana da Costa Maltez Henriquez, adjuntas effectivas Consuelo Guerreiro de Sant'Anna e Maria Magdalena de Souza Ferreira, que esta licenciada, sendo substituída pela professora Victoria Ferreira Pina (PARÁ, 1926, p. 6).

Partindo desse registro, identificamos o princípio fayolista da divisão do trabalho, que segundo Maximiano (2012) representa a distribuição de tarefas específicas para cada pessoa, uma vez que promove a especialização das funções e a divisão dos poderes. No caso dos grupos escolares, esse poder ficaria centralizado nas mãos do diretor, responsável por um estabelecimento marcado pela "fragmentação do currículo em graus e especialização ou divisão 
do trabalho dos professores" (FRAGO apud SOUZA, 2014, p. 107). Cada professor seria responsável por sua turma, sendo de responsabilidade da direção do grupo organizar e distribuir cada docente para sua respectiva turma e seção. Corroborando a nossa compreensão sobre esse princípio no âmbito escolar, Ribeiro (1938) revela que este era meramente burocrático e presente em vários momentos do cotidiano de um estabelecimento de ensino, como exemplo "o apparecimento de 'estado maior' compreendendo os directores, assistentes e auxiliares dos varios cursos" (RIBEIRO, 1938, p. 96).

Avançando na análise dos relatórios de Aurelia Franco, verificamos uma constante menção do Regulamento Geral de Ensino Primário e da exaltação dos esforços empreendidos pelos docentes e pela própria diretora.

Cumprindo o dispositivo do artigo $60 \int 28$ do Regulamento Geral de Ensino Primário, em vigor, faço chegar às mãos de V. Exª . para o devido julgamento, o seguinte relatório que trata da direção e do serviço interno deste estabelecimento que está sob minha orientação, e isto faço com todo prazer, cônscia que tenho satisfeito aquelle Regulamento e também correspondido com o apoucamento de minha inteligência, a confiança que me fôra dispensada. Julgo que se há feito alguma coisa aproveitavel com referência ao ensino, o que francamente observo na assiduidade, esforço e boa vontade do corpo docente e adiantamento dos respectivos esforços. E outro resultado não era de se esperar, visto que a frente do destino do nosso glorioso Estado está um homem sinceramente intencionado [...] do credito moral e intelectual da nossa terra e da futurosa mocidade que mais tarde será o forte baluarte do estremecido [...]. Outra confiança que muito nos alimenta é a dedicação e a pronta assistência que nos são prestadas por V. Exa (PARÁ, 1926, p. 1).

Nessa passagem, foi possível constatar os princípios de Fayol, tais como da autoridade, da responsabilidade, da disciplina e da hierarquia. Com relação à autoridade, Maximiano (2012) argumenta que está relacionada ao direito de mandar e ao poder de ser obedecido. De acordo com Ribeiro (1938), esse princípio se apresenta diferente no contexto escolar se comparado com a indústria, pois a "autoridade escolar junto dos seus subordinados é mais de orientação e collaboração do que de mando, propriamente dito” (RIBEIRO, 1938, p. 97).

Nesse sentido, na citação anterior de Aurelia Franco, são revelados aspectos da autoridade da diretora, na medida em que ela relata os acontecimentos do "estabelecimento que está sob [sua] orientação" (PARÁ, 1926, p. 1), como também ressalta a colaboração dos docentes com o trabalho que estava sendo desenvolvido naquele grupo escolar. A autoridade do cargo de diretor nessa época era vista como "uma sinecura, um fator de honra e distinção. O diretor era visto como uma autoridade do Governo" (SOUZA, 1998, p. 77-78). 
Articulado com o princípio da autoridade, temos o princípio da responsabilidade que, de acordo com Maximiano (2012), refere-se à sanção, que pode ser vista como uma recompensa ou penalidade proveniente do exercício do poder. Assim, conforme Ribeiro (1938), um princípio condiciona o outro, pois para responsabilizar o trabalho de alguém é necessário que se tenha autoridade sobre este. Ao mencionar a "confiança que [he] fôra dispensada" (PARÁ, 1926, p. 1) para exercer a direção do Benjamin Constant, Aurelia Franco revela seu prestígio como diretora e a autoridade que lhe foi conferida para administrar aquele grupo; como consequência, ela apresentava a responsabilidade de julgar ou elogiar o trabalho realizado por seus funcionários sobre o qual a diretora julga "que se há feito alguma coisa aproveitavel com referência ao ensino" (PARÁ, 1926, p. 1).

Outros princípios do Fayolismo que identificamos nas passagens do relatório da diretora Aurelia de 1925-1926 foram os da disciplina e da hierarquia que, segundo Ribeiro (1938), são resultantes da autoridade, na medida em que a disciplina no contexto escolar apresentaria duas concepções fundidas em uma. Para esse autor, "vemos as duas correntes interpretarem a disciplina assim: a primeira, como obediencia e signaes exteriores de respeito; a segunda como atividade, assiduidade e esforço" (RIBEIRO, 1938, p. 98).

Verificamos tais concepções de disciplina quando Aurelia Franco revela a obediência e confiança ao governo da época, ao qual confere os bons resultados do grupo que administra, pois "outro resultado não era de se esperar, visto que a frente do destino do nosso glorioso Estado está um homem sinceramente intencionado" (PARÁ, 1926, p. 1). Da mesma forma, ressalta outra concepção de disciplina relacionada a "assiduidade, esforço e boa vontade do corpo docente e adiantamento dos respectivos esforços” (PARÁ, 1926, p. 1).

A disciplina era patente nos grupos escolares. Todos deveriam respeitar as regras, tanto diretor quanto professores e alunos, e destes últimos era exigida uma "rígida disciplina, observada no bom comportamento verificado pela assiduidade, frequência, pontualidade, asseio, ordem, obediência, cumprimento dos deveres" (SOUZA, 2014, p. 109). Com relação à frequência dos alunos, constatamos também um rígido controle pela diretora, que tinha por incumbência informar ao Secretário Geral do Estado a maior e a menor frequência, bem como uma média entre ambas. Como verificamos na passagem a seguir: 
Matricula e frequência do $2^{\mathrm{a}}$ semestre de 1922 e $1^{\mathrm{a}}$ de 1923

1922_ $2^{\mathrm{a}}$ semestre

Matricula geral - 360

Matricula real - 345

Secção feminina - 192

II masculina - 168

Frequência maior - 305

II menor - 200

Media de frequência - 260 (PARÁ, 1923, p. 3-4).

Essas informações eram sistematizadas e publicadas nas mensagens que os governadores apresentavam ao Congresso Legislativo do Estado, conforme verificamos no quadro a seguir, no qual os dados apresentados pela diretora Aurelia no relatório de 1922 são reproduzidos na mensagem do governador Sousa Castro, em 1923.

\section{Tabela 1 - Demonstrativo da matrícula e frequência nos grupos escolares da capital e subúrbios, referente ao ano de 1922}

\begin{tabular}{|c|c|c|c|c|}
\hline \multirow{2}{*}{ NOMES DOS GRUPOS } & \multirow{2}{*}{ Matric. total } & \multicolumn{2}{|c|}{ FREQUÊNCIAS } & \multirow{2}{*}{ Média } \\
\cline { 3 - 4 } & & Maior & Menor & \\
\hline Barão do Rio Branco & 843 & 690 & 518 & 614 \\
\hline Floriano Peixoto & 574 & 423 & 324 & 318 \\
\hline José Verissimo & 469 & 363 & 246 & 309 \\
\hline Wenceslau Braz & 411 & 339 & 250 & 290 \\
\hline Benjamin Constant & 360 & 305 & 200 & 260 \\
\hline Ruy Barbosa & 325 & 272 & 192 & 241 \\
\hline Paulo Maranhão & 324 & 251 & 230 & 241 \\
\hline Escola Anexa & 135 & 117 & 86 & 99 \\
\hline Bezerra de Albuquerque (Pinheiro) & 270 & 231 & 177 & 204 \\
\hline Monsenhor Mancio (Mosqueiro) & 153 & 153 & 54 & 92 \\
\hline Santa Izabel & 181 & 169 & 101 & 142 \\
\hline Castanhal & 181 & 143 & 77 & 110 \\
\hline Total & 4.226 & 3.456 & 2.455 & 2.982 \\
\hline
\end{tabular}

Fonte: Adaptado de Pará (1923, p. 54).

No que concerne ao princípio da hierarquia, Maximiano (2012) o define como a constituição dos chefes, que vai do primeiro ao último escalão, sendo concedida aos subordinados de chefes "diferentes a autonomia para estabelecer relações diretas, estabelecendo o que Fayol [...] denominou de 'ponte"' (MAXIMIANO, 2012, p. 59). No grupo escolar, o diretor era o superior hierárquico daquele estabelecimento, era o detentor do poder central; porém, 
havia outras relações de hierarquias, a exemplo da existente entre o professor e os alunos, que deveriam ser obedientes à estrutura hierárquica e cumprir com seus deveres, mantendo sempre a disciplina e a ordem, como no ritual realizado antes do início das aulas, quando os alunos eram "perfilados no pátio, entoando o Canto de Entrada na presença do diretor e dos professores, era um dos quadros possíveis que marcavam o início do dia nos Grupos Escolares" (MITRULIS apud SOUZA, 2014, p. 127).

A relação hierárquica não ocorria apenas entre os membros internos do grupo, como também havia a subordinação entre o diretor e o Secretário Geral do Estado, e deste em relação ao Governador. Foi possível identificar o princípio da hierarquia no trecho em que a diretora Aurelia revela cumprir "o dispositivo do artigo 60 \28 do Regulamento Geral de Ensino Primário, em vigor” (PARÁ, 1926, p. 1), como também ao mencionar que estava apresentando o relatório "para o devido julgamento" do Secretário Geral do Estado, que era superior hierárquico de Aurelia Franco.

Ainda sobre os relatórios administrativos de Aurelia Franco, podemos inferir que há o princípio da unidade de direção, uma vez que este pode ser definido, segundo Maximiano (2012), sob o prisma de um único chefe e um único programa para um conjunto de operações que visam ao mesmo objetivo. Esse princípio é verificado no contexto dos grupos escolares, na medida em que a fiscalização diária era exercida por um "único administrador - o diretor - que zelava pela ordem e respeito à hierarquia e pelo bom funcionamento das aulas" (AZEVEDO; STAMATTO, 2012, p. 96). Esse administrador era a autoridade maior no grupo escolar, o representante do Estado, estando subordinado ao programa de Governo e devendo cumprir à risca as ordens advindas por meio de decretos ou do regulamento da Diretoria de Instrução Pública Primária do Estado. Em um atendimento claro a essa subordinação, encontramos várias passagens em que a diretora Aurelia demonstra cumprir o estabelecido em lei.

Em vista do decreto do Exmo.Snr. Dr. Governador do estado, foram suspensos os trabalhos escolares no dia 5 de setembro de 1922, em regosijo do centenário da nossa independência, distribuindo-se nesse, os boletins annuaes, os cartões prêmios e dois livros para os alunnos que melhores medias alcançaram nos exames de certificados elementares e primários, intitulados: "Aurelia de Seixas Franco" e "Benjamin Constant" (PARÁ, 1923, p. 1).

Outro aspecto destacado por nós diz respeito ao trabalho que o corpo docente vinha realizando no grupo, mesmo diante de dificuldades, como a falta de pagamento. Acerca do assunto, Aurelia Franco relata que 
muito se há trabalhado nesta casa de ensino em beneficio da instrucção do nosso estado, e, lastimando profundamente a situação financeira que atravessamos, causa única que concorre para o professorado experimentar difficuldades no assíduo comparecimento, vejo contudo a melhor boa vontade do corpo docente, boa vontade esta, alliada a intenção de todos os que aqui trabalham pelo desenvolvimento intellectual dos alunos matriculados neste grupo (PARÁ, 1923, p. 1).

Mesmo com essa dificuldade, percebemos a ênfase dada pela diretora ao certo grau de assiduidade dos docentes, corroborando o discurso que se pautava no patriotismo, mantendo firme a crença de que uma nova sociedade, firmada no amor à pátria e na confiança do progresso do país, era mais forte do que os problemas enfrentados, uma vez que, de acordo com Fayol (1989), o interesse do Estado sobrepõe ao interesse individual.

Essa falta de recebimento dos vencimentos por parte dos docentes aproximou-se também dos princípios da remuneração e da estabilidade do pessoal propostos por Fayol. Segundo Maximiano (2012), a remuneração do pessoal deve ser equitativa e a estabilidade pressupõe a conservação das equipes com a finalidade de promover o seu desenvolvimento.

Segundo Ribeiro (1938), tais princípios estão intimamente ligados e representam um problema importante e difícil de ser resolvido, pois

a difficuldade consiste em achar um criterio e é tão grande que na empreza escolar, acontece ás vezes, não se adoptar criterio nenhum. Para uns o criterio deve ser fundado nas necessidades do agente; para outros deve ser fundado nas possibilidades da empreza. Aqui, como em tudo, o mais prudente, sinão o mais verdadeiro, está no meio termo (RIBEIRO, 1938, p. 100).

Assim, mesmo os relatórios não apresentando dados concretos sobre a remuneração dos funcionários, no que diz respeito ao estabelecimento de um valor a ser recebido e aos critérios para tanto, constatamos que a falta de regularidade no pagamento dos salários afetava a estabilidade. Isso se dava porque, sem os salários, os professores não tinham condições de comparecer ao grupo escolar, tendo como consequência para o ensino a sua descontinuidade, o que trazia "muitos males porque [a descontinuidade] assume muitas vezes, caracter de opposição” (RIBEIRO, 1938, p. 101).

Para mediar esses possíveis conflitos, o diretor escolar deveria apresentar características do princípio fayolista da centralização, que definia ser necessário para o administrador um "equilíbrio entre a concentração de poderes de decisão no chefe, sua capacidade de enfrentar suas responsabilidades e a iniciativa dos subordinados" (MAXIMIANO, 2012, p. 59). Dessa forma, dentro dos grupos escolares, os comandos eram centralizados na figura do diretor; um "novo 
profissional do ensino primário, [que] veio ocupar um papel central na cena pedagógica e na estrutura hierárquico-burocrática" (PENTEADO; BEZERRA NETO, 2012, p. 86), e que era responsável, entre outras atribuições, por repassar "orientações gerais e procedia ao controle da higiene e da adequação dos trajes dos alunos" (MITRULIS apud SOUZA, 2014, p. 127). De sua parte, Aurelia Franco demonstrou equilíbrio entre a centralização do poder de decisão e uma capacidade de enfrentar as dificuldades - tendo até de custear alguns gastos necessários - e de tomar decisões em prol do ensino.

Cumpre-me dizer a V.Exa . que sinto embaraço para fazer funcionar com regularidade as aulas destegrupo, devido a falta de elementos indispensáveis a esse fim, e, não querendo paralysar os trabalhos escriptos, sobre [...] os de exames, foi-me necessário prover a $\mathrm{m}^{\mathrm{a}}$ custa, este estabelecimento de papel, giz, tinta, lápis, etc para attender os interesses de ensino (PARÁ, 1923, p. 2).

Em relação aos princípios fayolistas da ordem e da iniciativa, estes também se evidenciaram nos relatórios analisados. A ordem refere-se a "um lugar para cada pessoa e cada pessoa em seu lugar” (MAXIMIANO, 2012, p. 59). Já o princípio da iniciativa se faz presente pelo zelo e pela atividade exercida pelos agentes.

Já em relação à aplicabilidade desses princípios na esfera escolar, Ribeiro (1938) nos esclarece que ambos se completam, uma vez que

a ordem, na empresa escolar, é o que se repete: o horário, as classes, os programmas, o arranjo das salas, o trabalho e o esforço diarios, etc.; a iniciativa é a flexibilidade de tudo aquillo, de accordo com as opportunidades que surgem, os desdobramentos que se impõem, os rumos novos que se tomam conforme a coragem dos responsaveis. Uma e outra se completam, se auxiliam e se favorecem (RIBEIRO, 1938, p. 102).

Em seus relatórios, a diretora Aurelia revela ser fiel aos cumprimentos legais e à aplicação das determinações estipuladas por seus superiores, como releva o trecho a seguir, no qual enfatiza a obediência ao que foi estipulado pelo Governador por meio de decreto.

Por decreto do Exmo. Dr. Governador do Estado foi marcado o período de 3 a 20 de novembro de 1925 para effectuarem-se os exames nos grupos escolares, obedecendo a seguinte ordem: de 3 a 9 exames de passagem de anno, de 10 a 14 de estados elementares e de 17 a 25 de estudos primários, sendo observadas as determinações do Regulamento Geral de Ensino Primário (PARÁ, 1926, p. 3-4). 
No discurso acerca da Instrução Pública da época, se transmitia a ideia de que o ensino ministrado nos grupos escolares seria responsável pela formação de "homens de ação, de trabalho, verdadeiros cidadãos republicanos, promotores da ordem e do progresso" (AZEVEDO; STAMATTO, 2012, p. 85). Tal discurso não se limitava ao ambiente escolar, uma vez que os grupos realizavam muitas apresentações que eram abertas para toda a sociedade. Assim, a ordem era um princípio norteador para que o povo daquela época alcançasse o almejado progresso.

Revelando ser uma cumpridora das leis, preocupada em manter a ordem e a disciplina, a diretora Aurelia manifesta em certos trechos de seus relatórios características do princípio fayolista da equidade, o qual propõe que haja um "tratamento das pessoas com benevolência e justiça, não excluindo a energia e o rigor quando necessários" (MAXIMIANO, 2012, p. 59). Esse princípio é revelado nos relatórios, principalmente quando Aurelia Franco reconhece o trabalho realizado pelas professoras e faz elogios: "É meu dever louvar as professoras adjunctas Auta do Nascimento Braga, Izaura Cavallero da Silva e Victoria Ferreira Pina que, como substitutas, deixaram na sua curta trajetória por esse grupo bem patentes os seus méritos de educadoras" (PARÁ, 1926, p. 7).

Por fim, conforme Ribeiro (1938), o princípio fayolista do espírito de equipe (união) é uma consequência do princípio da equidade, uma vez que a união é "feita pela harmonia dos agentes, pela bôa vontade reciproca de cada um e pelo espirito de solidariedade e de amizade mesmo" (RIBEIRO, 1938, p. 104). Nesse sentido, há passagens dos relatórios em que a diretora Aurelia relata a união de todos os segmentos em momentos festivos do grupo Benjamin Constant.

Como vê V.Exa não poupa esforços nem também encontro da maior parte dos professores o desfalecimento que quase sempre aparece quando aos subordinados, cabeças pensantes, corações que vibrem de orgulho e prosperidade pelo estremecido Brasil. As duas melhores festas realizadas no $2^{\circ}$ semestre de 1926 foram: a chegada do Dr. Washington Luiz, presidente eleito do nosso Brasil e a do encerramento das aulas e entrega dos prêmios de honra, ambas levadas a effeito no campo do club do Remo (PARÁ, 1927, p. 3).

Nessa passagem, Aurelia Franco expõe uma característica marcante dos grupos escolares que era a realização das festas de caráter cívico e patriótico com a finalidade de promover os ideais republicanos. Esses eventos representavam ritos comuns nos grupos escolares, com a finalidade de legitimar os ideais republicanos perante a sociedade da época "criando uma espécie de tradição compreendida esta como fruto do projeto político e civilizador da República, entendido aqui como inaugurador de determinados costumes, que seriam materializados mediante a educação" (AZEVEDO; STAMATTO, 2012, p. 88-89). Pelo exposto, cumpre 
destacar que utilizamos, em nossa pesquisa, os princípios de Fayol (1989) na tentativa de identificarmos características da administração realizada dentro do Grupo Escolar Benjamin Constant na segunda década da Primeira República por meio de aproximações com as teorias de administração vigentes à época.

\section{CONSIDERAÇÕES FINAIS}

Procuramos, neste trabalho, analisar a administração do Grupo Escolar Benjamin Constant entre os anos de 1922 e 1927, baseando-nos nos relatórios da diretora Aurelia de Seixas Franco, por meio dos quais foi possível identificar, na legislação vigente, as competências do diretor escolar, compreender o cenário histórico em que estavam inseridos os estabelecimentos de ensino e identificar princípios fayolistas de administração.

Para o regime político que se instaurava, fazia-se necessário um novo modelo de ensino e de estabelecimentos especializados, o que deu origem ao surgimento dos Grupos Escolares, instituições pautadas por uma instrução voltada para a disciplina e a obediência. Sua finalidade era desenvolver nas crianças virtudes morais e cívicas, valores que, segundo os republicanos, iriam auxiliar na formação de uma sociedade baseada na ordem e no progresso do país. É importante destacar que nos deparamos com a ausência de uma teoria de administração escolar mais específica do período da Primeira República brasileira, pois, como Sander (2007) ressalta, as primeiras teorias acerca do assunto só foram formuladas após os anos 1930. Em razão disso, buscamos situar as características da administração do Grupo Benjamin Constant por meio de aproximações com as proposições de Fayol.

Destacamos nos relatórios da diretora Aurelia as passagens que revelam o grau de autoridade de que ela estava investida. Marcantes também foram as inferências sobre as péssimas condições do prédio, a falta de material escolar e as dificuldades financeiras dos docentes, o que revelou o cenário econômico de profunda crise pelo qual passava o Estado. Essa situação refletia-se na sociedade paraense e afetava inclusive a instrução pública daquela época, o que agravou ainda mais a dificuldade de administrar um estabelecimento escolar em meio a péssimas condições de trabalho.

No entanto, mesmo com o quadro negativo em relação à economia, a direção continuava com sua missão de ajudar o novo regime político a consolidar o ideal republicano de sociedade. Fiel à sua incumbência, Aurelia expõe em algumas passagens de seus relatórios o "amor à pátria" e a "crença” em tempos melhores, o que está relacionado ao princípio do interesse geral do fayolismo, pois, mesmo em situações precárias de trabalho, a diretora animava seus docentes 
a se manterem resilientes e crentes no futuro "glorioso" do Estado, de modo a incutir nos alunos um sentimento de respeito, de dedicação e amor ao país, em plena consonância com os valores morais e cívicos para a formação do cidadão republicano.

Em síntese, administrar um Grupo Escolar e ser diretora naquela época era uma tarefa que exigia de Aurelia Franco o perfil de uma militante da causa republicana, credora das melhorias que o regime traria, ainda que tardiamente, à sociedade paraense, mesmo que em clara contradição com as condições precárias sob as quais o governo mantinha a instrução pública e seus respectivos estabelecimentos, situação resultante do descaso do Estado em relação a esse setor do governo. Todavia, é possível entrever nas palavras da diretora uma diferença significativa entre um início mais desesperançoso e preocupado, e um término mais esperançoso e confiante a respeito do período estudado. É certo que foram tempos marcados por contradições, pois, de um lado, eram evidentes os ideais republicanos da ordem e do progresso como base para a educação/ formação do novo cidadão e, de outro, contrapunha-se uma economia em plena crise como resultado da queda dos preços da borracha no mercado internacional. Dentro desses limites, os relatórios da diretora Aurelia nos revelaram a situação precária de uma instituição representativa dos grupos escolares paraenses em razão do pouco ou nenhum investimento. Por fim, mesmo que esses documentos apresentem limitações devido à sua própria natureza oficial, podemos destacar que se constituíram indubitavelmente em instrumentos utilizados pela diretora, ainda que de forma discreta, para apontar os problemas vivenciados pela administração escolar naquela época.

\section{REFERÊNCIAS}

AZEVEDO, Crislane Barbosa de; STAMATTO, Maria Inês Sucupira. Escola da ordem e do progresso: Grupos escolares em Sergipe e no Rio Grande do Norte. Brasília: Liber Livro, 2012.

CARVAlHO, Carlos Henrique. República e imprensa: as influências do positivismo na concepção de educação do professor Honório Guimarães (Uberabinha-MG 1905 - 1922). Uberlândia: EDUFU, 2004.

COELHO, Maricilde Oliveira. A escola primária no estado do Pará (19201940). 2008. 205 f. Tese (Doutorado em Educação) - Universidade de São Paulo, São Paulo, 2008. 
DOLL JR, William E. Os remanescentes do currículo. In: Currículo: uma perspectiva pós-moderna. Porto Alegre: ArtMed, 2002. p. 55-68.

DOURADO, Luiz Fernandes. Políticas e gestão da educação básica no Brasil: Limites e perspectivas. Educação e Sociedade, Campinas, v. 28, n. 100, p. 921 946, out. 2007.

FAYOL, Henri. Administração industrial e geral: previsão, organização, comando, coordenação, controle. 10. ed. São Paulo: Atlas, 1989.

LÜCK, Heloisa. Perspectivas da gestão escolar e implicações quanto à formação de seus gestores. Em Aberto, Brasília, v. 17, p. 11-33, fev./jun. 2000.

MAXIMIANO, Antonio Cesar Amaru. Teoria Geral da Administração. São Paulo: Atlas, 2012.

NOSELLA, Paolo; BUFFA, Ester. Instituições Escolares: porque e como pesquisar. Campinas: Alínea, 2009.

PARÁ. Relatório do Grupo Escolar Benjamin Constant 1922-1923. Belém: Imprensa Official, 1923.

PARÁ. Relatório do Grupo Escolar Benjamin Constant 1925-1926. Belém: Imprensa Official, 1926.

PARÁ. Relatório do Grupo Escolar Benjamin Constant 1926-1927. Belém: Imprensa Official, 1927.

PARO, Vitor. Administração escolar: introdução crítica. 17. ed. São Paulo: Cortez, 2012.

PENTEADO, Ana Elisa de Arruda; BEZERRA NETO, Luiz. História da Administração Escolar no Brasil. Campinas: Editora Alínea, 2012.

REBELATTO, Durlei Maria Bernardon. Trajetória da administração educacional no Brasil: tessituras, rupturas e continuidades. In: COLÓQUIO INTERNACIONAL DE EDUCAÇÃO, 4., 2014, Laranjeiras. Anais... Joaçaba: UNOESC, 2014. p. 321-334. 
RIBEIRO, José Querino. Fayolismo na Administração das Escolas Públicas. São Paulo: Linotechina, 1938.

SANDER, Benno. Administração da Educação no Brasil: genealogia do conhecimento. Brasília: Liber Livro, 2007.

SOUZA, Rosa Fátima de. Templos de civilização: a implantação da escola primária graduada no estado de São Paulo: (1890-1910). São Paulo: Fundação Editora da UNESP, 1998.

SOUZA, Rosa Fátima de. Lições da escola primária. In: SAVIANI, Dermeval et al. (Org.). O legado educacional do século XX no Brasil. 3. ed. Campinas: Autores Associados, 2014. p. 101-141.

TEIVE, Gladys Mary Ghizoni; DALLABRIDA, Norberto. A escola da República: os grupos escolares e a modernização do ensino primário em Santa Catarina (1911-1918). Campinas: Mercado de Letras, 2011.

WAHRLICH, Beatriz Marques de Souza. Uma análise das teorias de organização. 3. ed. Rio de Janeiro: Fundação Getúlio Vargas, 1974.

\section{Monika Reschke}

Doutoranda pelo Programa de Pós-Graduação em Educação na Amazônia - EDUCANORTE. Professora da Secretaria Municipal de Educação de Ananindeua (SEMED). Vice Diretora na Escola Estadual Benjamin Constant. Vice coordenadora do Laboratório de Pesquisas em Memória e História da Educação (LAPEM) do Núcleo de Estudos Transdisciplinares em Educação Básica da Universidade Federal do Pará. E-mail: monikareschke@hotmail.com

\section{Alberto Damasceno}

Doutor em Educação pela Pontifícia Universidade Católica de São Paulo. Professor Titular da Universidade Federal do Pará, docente do Programa de Pós-graduação em Currículo e Gestão da Escola Básica (PPEB) e do Programa de Pós-graduação em Educação na Amazônia (PGEDA). Coordenador o Laboratório de Pesquisas em Memória e História da Educação (LAPEM) e é vice-coordenador do Grupo de Estudos em Educação no Pará na Primeira República (GEPRE).E-mail: albertod@ufpa.br 